\title{
Lung Function Assessment by Impulse Oscillometry in Adults
}

This article was published in the following Dove Press journal:

Therapeutics and Clinical Risk Management

\section{Noemi Porojan-Suppini (D) \\ Ovidiu Fira-Mladinescu (D) \\ Monica Marc (ID \\ Emanuela Tudorache \\ Cristian Oancea}

Department of Pulmonology, Center for Research and Innovation in Personalized Medicine of Respiratory Diseases, University of Medicine and Pharmacy "Victor Babeș", Timișoara, Romania
Correspondence: Ovidiu Fira-Mladinescu Department of Pulmonology, University of Medicine and Pharmacy "Victor Babeș", Str. Gheorghe Adam nr. 13, Timișoara 300310 , Romania

Tel +40745608856

Email mladinescu@umft.ro

\begin{abstract}
Over the past decades, impulse oscillometry (IOS) has gained ground in the battery of pulmonary function tests. Performing the test requires minimal cooperation of the patient; therefore, it is a useful tool, especially in evaluating lung mechanics in children, elderly patients, and those who cannot perform spirometry. Oscillometry has also been used in both clinical and research departments. Studies were published mainly in asthma regarding detection of bronchodilator response and the therapeutic response to different drugs. Furthermore, it has been shown to be a sensitive technique to evaluate disease control. Other studied diseases were COPD, interstitial lung diseases, small airway disease, impairment of lung function due to exposure to occupational hazards or smoking, central airways obstruction, cystic fibrosis, monitoring lung mechanics during mechanical ventilation and sleep, neuromuscular diseases, lung transplant, and graft function. The aim of this review is to present the utility of oscillometry on the previously mentioned clinical fields.
\end{abstract}

Keywords: oscillometry, pulmonary function tests, respiratory resistance, respiratory impedance

\section{Introduction}

In the exploration of respiratory mechanics, the forced oscillation technique (FOT) is very often included in routine lung function testing, due to its minimal demand for the patient's cooperation. It is performed during tidal breathing, giving details on the respiratory system's elastic proprieties and homogeneity of ventilation. The principle of the maneuver is using external pressure signals (usually generated by a loudspeaker) to measure flow-response of the respiratory tract. Pressure and the resulting flow are then studied, submitting parameters of oscillatory mechanics (resistance, reactance). The aim of this article is to present clinical applications of oscillometry in adult respiratory pathology.

\section{Structure of the Oscillometry System}

There are three perspectives of the forced oscillation technique, one of them is the "typical forced oscillometry technique", which is sometimes applied as a general term describing all oscillometry techniques, but commonly points out a simple onefrequency technique, ${ }^{1}$ another one is impulse oscillometry (IOS), using pressure pulses, and the third one is the Pseudo-Random Noise (PRN). IOS and PRN techniques are more often used because their principle allows a quick performance of the test. The one-frequency FOT is appropriate for the use in research because of its ability to determine changes occurring at one precise frequency. The concept of 
oscillometry was published very first by Dubois et al in 1956, describing a technique meant to be useful in acquiring data of the respiratory system's mechanic proprieties. ${ }^{2}$ Further studies were published after 1990, due to the development of technology, facilitating the technical approach and the interpretation of clinical data. ${ }^{3,4}$

The main components of the oscillometer (Figure 1) are the loudspeaker, which forms a pulsatile stimulus through the adapter, this way pressure waves get into the airways with the airflow; and the pneumotachograph, usually attached to a mouthpiece, a face mask, or an endotracheal tube. A bias flow is used to eliminate the dead space. Data will be collected by the pressure and flow sensors. ${ }^{5,6}$

\section{Technique Description}

Prior to the measurements, reasonable instructions should be given, patients should breathe with tidal volume and respiratory frequency as usually. The procedure should be executed with the subject seated in a relaxed but upright posture. The position of the head and neck should be neutral or a bit extended. The subjects have to support their cheeks firmly, and a nose-clip must be used. ${ }^{7}$ The technician must perform a visual check in order to verify that the mouthpiece is sealed and the tongue is in correct position, so there are no leaks around the mouth. During the procedure, the subjects are asked to perform tidal breathing for 30-45 seconds. Provided values of impedance are typically an average of all recorded correct measurements acquired in the course of the testing interval. ${ }^{3,8}$ King et $\mathrm{al}^{8}$ published technical standards for respiratory oscillometry in 2019 , including a list of minimum instructions and information that should be provided to the patient prior to testing. Usually three measurements need to be performed, although in a study conducted by Watts et al, ${ }^{9}$ published in 2016, analyzing the effect of the period of data gathering during the measurements on FOT results, 22 asthmatics, 18 COPD patients, and 20 healthy patients were used for the control group. Their study showed that two technically sustainable measurements derive the same mean resistance and reactance values as three or more replicate measurements, no matter how long the measurement lasts. Special attention is needed when performing multiple pulmonary function tests. Numerous studies proved that volume history can affect measurements in the case of subjects with pulmonary pathology, and in the case of healthy subjects during bronchoprovocation tests. Jensen et $\mathrm{al}^{10}$ published a study showing the effects of deep breaths and bronchial challenge on airway caliber. Their study showed that asthmatic subjects cannot maximally dilate their airways during deep inspiration, and this worsens post-constriction considerably. Salome et $\mathrm{al}^{11}$ also published a study 2 years later demonstrating theeffects of airway re-narrowing for asthmatic and non-asthmatic patients. Slats et $\mathrm{al}^{12}$ published a study showing that, in the case of asthmatic patients, inflammation in the airways is strongly associated with impaired mechanical function of the lungs through deep inspiration. Therefore, oscillometry should be performed before other pulmonary tests requiring the subject to take deep breaths.
A. Loudspeaker

B. Bias flow

C. Pneumotachograph

D. Airflow

E. Airway opening pressure

F. Mouthpiece and bacterial filter

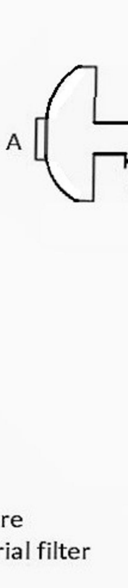

B
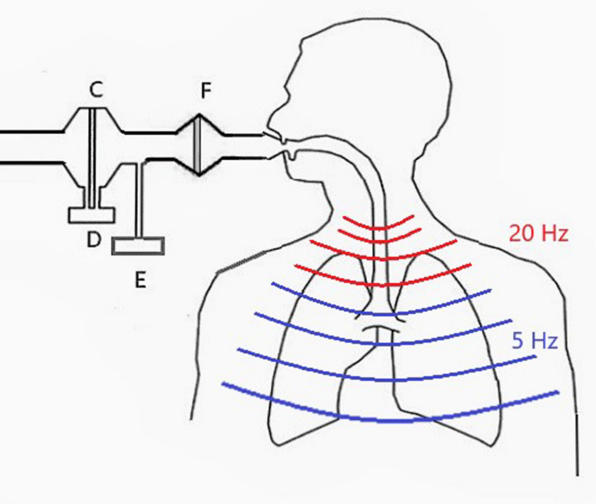

Figure I 


\section{Acceptability Criteria}

Although acceptability and reproducibility criteria of oscillometry still need improvement, the accuracy of the impedance measurements can be obtained by quality control, excluding artifacts such as swallowing, glottis closure, poor cheek support, tongue movement, or the presence of leaks. Technicians can identify these artifacts by monitoring the flow, the volume, and the pressure during the procedure, and eventually repeating the measurements, until obtaining three accurate recordings. ${ }^{8,13}$ Reproducibility of impedance can be validated with coherence values. An optimal test quality requires values larger than $0.8 \mathrm{~cm} \mathrm{H}_{2} \mathrm{O}$ measured at $5 \mathrm{~Hz}$ or larger than $0.9 \mathrm{~cm} \mathrm{H}_{2} \mathrm{O}$ measured at $20 \mathrm{~Hz}^{8}$

\section{Parameters}

The respiratory tract's resistance and reactance values can be determined by oscillometry at given frequencies. The main parameters are: Impedance $(Z)$ force that has to be defeated in order to mobilize gas in and out of the airways. Mathematically it can be determined as the ratio of pressure $(\mathrm{P})$ to flow $(\mathrm{V})$ in function of oscillation frequency $(\omega)$ :

$$
Z(\omega)=\frac{P(\omega)}{V(\omega)} 14
$$

Furthermore, impedance can be separated to its components, resistance $(\mathrm{R})$ and reactance $(\mathrm{Z})$ :

$$
Z(\omega)=R(\omega)+j X(\omega)^{14}
$$

where j-imaginary unit, $\sqrt{ }-1$.

Variations of impedance can be detected depending on the respiratory tract area where the pressure is measured (upper airways, distal airways, lungs, or chest-wall). ${ }^{15,16}$ Respiratory resistance (Rrs) is the energy needed to move the pressure wave through the airways. An increase in resistance can be found in diseases affecting the airways, for example in asthma or COPD. Respiratory reactance (Xrs) is the energy determined by flow airflow dynamics in the airways, influenced by the elasticity of tissue and the interstitial forces. Values of reactance (Xrs) become more negative in diseases where elastance is increased.

$$
X(\omega)=I-\frac{E}{\omega}{ }^{14}
$$

where Capacitance (E), component of reactance, determines the elasticity of the lung, and it presents as a negative value. Inertance (I), also part of reactance, is determined by mass-inertive forces of the air movement in airways and it is a positive value.
Resonance frequency (Fres) is the value of Hertz at which inertance and peripheral capacitance of the lungs have equal values, and the total reactance becomes zero. ${ }^{17}$ Reference values of resonance frequency for adults are between 7 and $12 \mathrm{~Hz} \cdot{ }^{5,17}$ Values of resonance frequency can be higher in the case of lung disorders, both restrictive and obstructive. ${ }^{18,19}$ The area of reactance (AX) includes the area under the reactance curve from lowest frequency to Fres; increased values were correlated with distal obstruction.

Practically $5 \mathrm{~Hz}$ frequency signals reach distal airways so R5 equals the total airway resistance, while highfrequency signals like $20 \mathrm{~Hz}$ can only reach the central airways and R20 equals the resistance of the proximal airways (Figure 2). In order to acquire the resistance of the distal airways, the difference between R5 and R20 is needed. ${ }^{18,20}$ In practice, a higher increased R5 than R20 means the disease of small airways, and the increase of both parameters (R20 and R5) indicates proximal airway disease. ${ }^{15,18,20}$ On the other hand, reactance (Xrs) at low frequencies $(5 \mathrm{~Hz})$ determines the elastic and interstitial proprieties of the lung. Diseases that affect the elasticity of the lung (for example: interstitial lung diseases) will increase capacitance negatively (X5 will be more negative). Values of reactance are also influenced by age and weight (increase of age and weight will determine a less negative reactance).

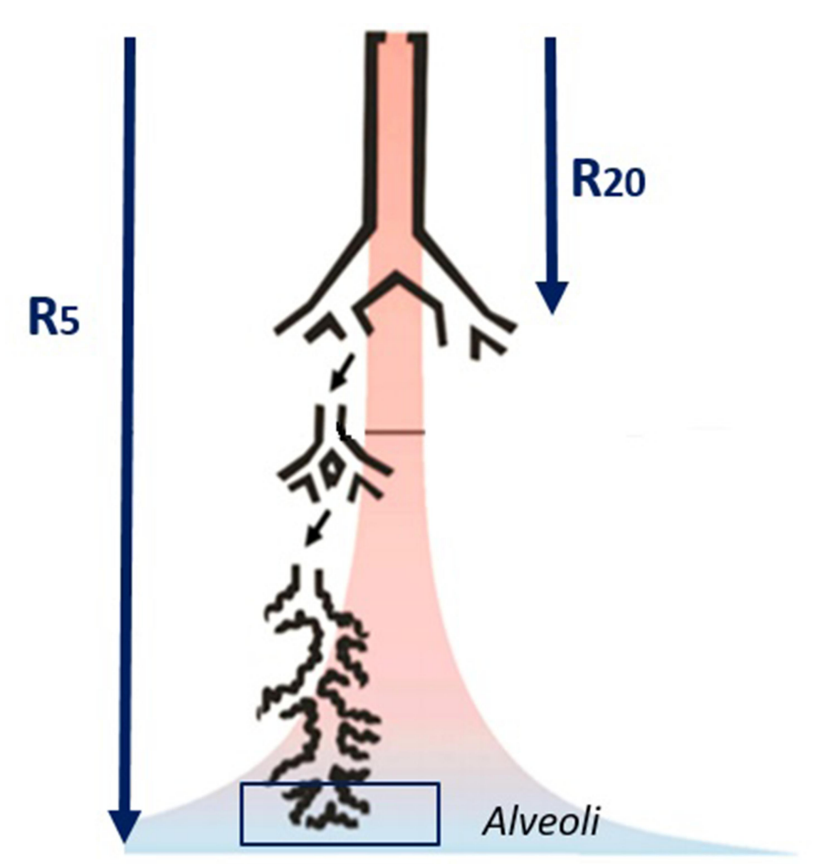

Figure 2 


\section{Interpretation and Reference Values}

Last year the European Respiratory Society elaborated new "technical standards for respiratory oscillometry". King et $\mathrm{al}^{8,21}$ recommend in their article determination of predicted values for any oscillometry device in the population where it is used. Values can be different depending from the type of device that is used. ${ }^{22,23}$ Although there are publications on reference values, especially in the case of children, but also in the case of adults, normative values have not yet been published. ${ }^{8}$ Kalchiem-Dekel and Hines ${ }^{24}$ published a review article on reference values for oscillometry collecting published data from 1977 to 2017. In their research they included 14 studies of forced oscillometry technique, 19 studies of impulse oscillometry, and one study providing values for both. The majority of publications were from Europe and Asia, applied on small groups of subjects (median=264 subjects). They concluded that the measurements and the test performance were inconstant. Prediction equations were influenced by the height of the subjects and also by the gender. The age variation was not conclusive due to the poor representation of elderly subjects in the studies. A German study conducted by Sulhz ${ }^{25}$ on a large number of subjects (1990), aged between 45-91 years, established significant differences in values of Rrs5 (29\%), Rrs20 (33\%), and Xrs5 (76\%) compared to previous publications. In Table 1 we summarized the main publications on reference ranges since 2010, with over 250 subjects. Difficulties in interpretation may appear in the presence of a lung disorder, due to lack of recognizing different disease patterns. A Canadian study conducted by Dandurand et $\mathrm{al}^{26}$ demonstrated that there are significant differences between oscillometry devices and measurement performances, reducing the ability to compare between studies using different equipment and formation of oscillometricparameter databases device-independently. There are also situations when subjects performing the test have multiple lung diseases (overlap).

\section{Clinical Applications}

The main areas of clinical application of impulse oscillometry are presented in Figure 3.

\section{Response to Broncho-Dilatators}

One of the main utilities of oscillometry is assessing broncho-dilatator (BD) response. Studies showed that FOT has more sensitivity than spirometry in the case of children as a predictor of asthma and response to treatment. ${ }^{16,27}$ When evaluating BD response, King et al ${ }^{8}$ recommend the definition of a positive response as a decrease in Rrs5 with $-40 \%$, an increase in Xrs5 with $+50 \%$ and decrease in AX with $-80 \%$. da Costa et $\mathrm{al}^{28}$ studied the impedance changes after administration of salbutamol in the case of healthy and COPD patients, showing that oscillometric parameters are highly sensitive to broncho-dilatation, especially in early stages of COPD. Another study conducted in Japan by Inui et $\mathrm{al}^{29}$ showed that FOT can be as useful as spirometry in assessing treatment response to treatment of COPD patients. An Australian study assessed the broncho-dilatator effects on exertional dyspnea, showing improvement, and also increased conductance values measured by FOT in case of moderate-COPD patients. ${ }^{30}$ Milne et $\mathrm{al}^{31}$ published a small study, on 15 COPD patients assessing correlations

Table I Main Publications Reporting Reference Values on Healthy Adults Since 2010

\begin{tabular}{|c|c|c|c|c|c|c|}
\hline Authors & Technique & $\begin{array}{l}\text { Frequency } \\
\text { Range (Hz) }\end{array}$ & $\begin{array}{l}\text { Number of } \\
\text { Subjects }\end{array}$ & $\begin{array}{l}\text { Age } \\
\text { Range }\end{array}$ & $\begin{array}{l}\text { Etnicityl } \\
\text { Nationality }\end{array}$ & Parameters \\
\hline Brown et al, $2010^{103}$ & FOT, PRN & $6-19$ & 904 & $18-92$ & Caucazian & R6, RII, RI9, X6, XII, XI9 \\
\hline Fujiwara, $2010^{104}$ & IOS & $5-35$ & 420 & $20-89$ & Japanese & R5, R20, FDRrs, $X 5$ \\
\hline Crim et al, $2011^{53}$ & IOS & $5-20$ & 555 & $55 \pm 9$ & Multinational & R5, R20, FDRrs, X5, AX, Fres \\
\hline $\mathrm{Li}$ and Wang,2012 $2^{105}$ & IOS & $5-20$ & 920 & $56 \pm 13$ & Chinese & R5, R20, FDRrs, $X 5$, Fres \\
\hline Oostveen et al,2013 $3^{21}$ & IOS, PRN & - & 368 & $18-84$ & Caucazian & $\begin{array}{l}m R r s, m X r s, \text { Fres, } A X \text { mRrs, R4-R26, } \\
X 4-X \mid 4 \text {, Fres, AX4, AX5 }\end{array}$ \\
\hline Schulz et al,201 $3^{25}$ & IOS & $5-35$ & 397 & $45-91$ & Caucazian & R5, R20, FDRrs, $X 5, A X$, Fres \\
\hline Xue, $2014^{24}$ & IOS & - & 6945 & $40-65$ & Chinese & mZrs, R5, X5, Fres \\
\hline Zheng et al2015 $5^{24}$ & IOS & $5-20$ & 362 & $18-78$ & Chinese & R5, R20, X5, X20, Fres \\
\hline Geng et al,2016 $6^{24}$ & IOS & $5-20$ & 409 & $20-60$ & Chinese & R5, R20, X5, Fres \\
\hline Shu et al,2016 $6^{24}$ & IOS & $5-20$ & 431 & $48 \pm 14$ & Chinese & R5, R20, FDRrs, X5, Fres \\
\hline Ribeiro et al,2018 $8^{106}$ & PRN & $4-32$ & 288 & $20-86$ & Brazilian & $R 4, R 22, \times 8, \times 22$ \\
\hline
\end{tabular}




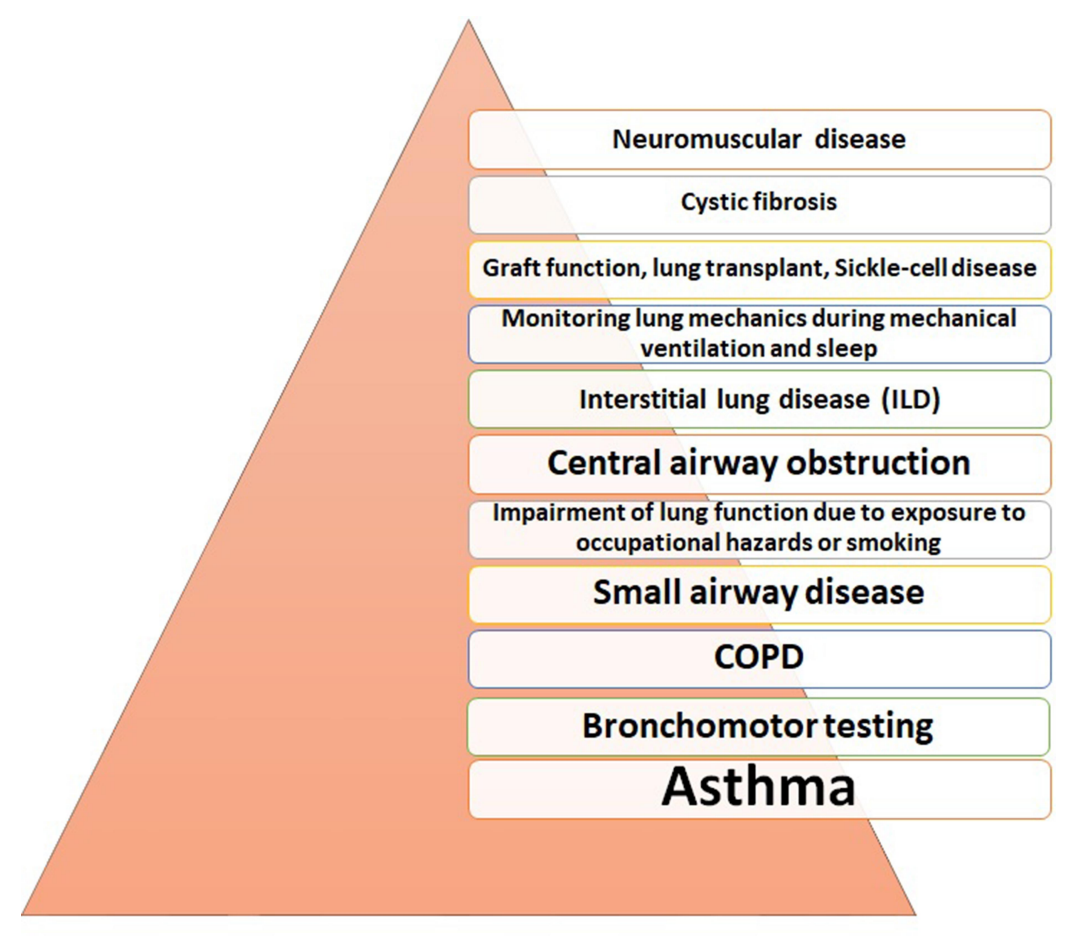

Figure 3

between oscillometry, hyperinflation and air-trapping in response to long-acting broncho-dilatator treatment and demonstrating its utility in treatment response evaluation as a complementary functional test. Assessing the responsiveness of airways to combined therapy (long-acting beta agonists and corticosteroids) in asthma was the subject of numerous publications. ${ }^{32-34}$ The improvement of oscillometric parameters, and their prediction of improvement in FEV1 in the case of untreated asthmatic patients after a 2-month-administration of combined therapy (corticosteroids and long acting beta-agonists) was shown in a Japanese study published by Akamatsu et al. ${ }^{35}$

\section{Broncho-Provocation Testing}

Broncho-provocation testing can be performed in order to assess airway hyper-responsiveness using various agents like histamine, methacholine, allergens, and also by exercise testing. An increase of oscillometryc parameters like Rrs5, AX, and Fres has been demonstrated; Xrs5 became more negative during exercise-induced bronchoconstriction. Segal et $\mathrm{al}^{36}$ revealed that hyper-reactivity of distal airways can be connected to methacholine-induced symptoms without any change in FEV1. This study highlights the importance of disparity between proximal and distal airway behavior. A study conducted by Mandelev et $\mathrm{al}^{37}$ showed that in the case of obese subjects, bronchial challenge is related to higher expiratory flow limitation measured by Xrs. It has been established that the obtained values correspond rather with symptoms than with values of FEV1. ${ }^{38}$ Studies have also shown that an increase of initial Rrs5 values of $50 \%$ after broncho-provocation may be correlated with a $20 \%$ decrease in FEV1. ${ }^{8,-32,-39-41}$ A study published by Naji et $\mathrm{al}^{42}$ concluded that using oscillometry as an alternative method for measuring resistance and obstruction may be useful when patients cannot perform body-plethysmography or spirometry. Figure 2 illustrates the disease variety in which impulse oscillometry has been proved useful.

\section{Asthma and COPD}

The most often researched lung diseases with oscillometry of all is asthma. Airway resistance increases (especially in small airways) in the case of patients with asthma, mainly during exacerbations. ${ }^{17}$ Usually there are increased values of Rrs5, Fres, normal values of R20, and Xrs5 is more negative ${ }^{17}$ In periods between exacerbations all parameters may be normal in the case of children. ${ }^{43}$ Oscillometry is also a useful tool in evaluating the control level of asthma. Poor control of the disease can be suspected when parameters Rrs5-Rrs20 and AX are increased. ${ }^{43}$ A Spanish study concluded that there were important parameter differences in case of uncontrolled, poorly controlled, and 
uncontrolled asthma, but patients cannot be organized correctly into control categories only based on oscillometry. They found associations between oscillometric values and spirometry. ${ }^{27}$ Similar data was published by Galat et $\mathrm{al}^{44}$ in a review article on asthma control. Carr et $\mathrm{al}^{45}$ reviewed literature on the correlation between small airways disease and asthma control, concluding that diagnose of SAD (small airway disease) can occur with various non-invasive tests, including oscillometry, and may improve treatment response. Furthermore, oscillometry may detect small airways impairment even before the presence of symptoms and spirometric changes. ${ }^{15,46} \mathrm{It}$ can be useful in preventing symptom development by implementing prompt therapy. ${ }^{46}$ Detecting treatment response in asthma is also a feature of oscillometry, especially by assessment of the changes in the reactance area (AX) ${ }^{47}$

In contrast, in the case of COPD patients a higher increase in Rrs5 than in Rrs20 was noticed, leading to elevation to the Rrs5-Rrs20 parameter. ${ }^{48-51}$ Reference values for this disease were also studied, but there are not any defined values yet. Cut-off pathological values for R5 higher than $0.5 \mathrm{kPa} / \mathrm{L} / \mathrm{s}, \mathrm{R} 5-20$ higher than 0.10 $\mathrm{kPa} / \mathrm{L} / \mathrm{s}, \mathrm{AX}$ higher than $1.0 \mathrm{kPa} / \mathrm{L}$ were suggested for use, but further studies are required. ${ }^{48,52}$ Also in COPD, the magnitude of the changes in Fres, Rrs5, Rrs20, Xrs5, and AX tends to correlate well with GOLD1-GOLD4 severity. This was shown in the largest study (Eclipse study, a 2,054 cohort of COPD patients) performed by Crim et al. ${ }^{53}$ A Chinese study performed on 215 subjects with COPD by Wei et $\mathrm{al}^{52}$ comparing the usefulness of IOS and other pulmonary function tests in determination of the severity of disease showed that there is a good correlation between tests, especially with reactance parameters, and that IOS may be used as an alternative diagnostic test in case of patients with FEV1 lower than 50\%. A study published in Poland by Piorunek et $\mathrm{al}^{54}$ suggests that the severity of obstruction in COPD measured by spirometry (FEV1\% pred.) correspond with oscillometric parameters, and lung resistance is influenced by airflow limitation severity. Eddy et $\mathrm{al}^{55}$ studied the correlation between impulse oscillometry and hyperpolarized gas magnetic resonance imaging (MRI) of ventilation defects. Their study showed that parameters R5-19 and X5 may correspond with airway and parenchymal disease-specific abnormalities causing ventilation defects. The frequency of COPD exacerbations was correlated with increasing parameter AX. ${ }^{48}$ Although oscillometry's role in diagnosis of obstructive diseases is known, there are some limitations of this technique in monitoring the disease progress that needs further study. ${ }^{20}$

\section{Interstitial Lung Disease (ILD)}

Modified values of reactance and resistance can appear in consequence of small airways inflammation, or in association with modified elastic recoil pressure and reduced lung volume in both obstructive and restrictive diseases. ${ }^{56}$ There is an overlap of increased parameters Rrs5, Fres, AX, and a decrease in Xrs5 (more negative) in both obstructive and restrictive lung diseases, this could be a reason why oscillometry has a bigger role in characterizing obstructive diseases. ${ }^{57}$ The only parameter that differentiates them is Rrs20, which remains normal in the case of ILD patients, but increases in obstructive diseases. $^{58,59}$ In a study by Mori et al, ${ }^{60}$ decreased $\mathrm{X}$ values (especially $\mathrm{X} 5$ ) were found in patients with ILD, mostly in inspiration, which has more negativity than in expiration, in contrast to patients with COPD, which had decreased values in expiration that is more negative than in inspiration. A Japanese study conducted by Mikamo et $\mathrm{al}^{61}$ showed that oscillometry may be a useful tool in assessment of small airways disease in interstitial lung disease. A very recent study, conducted by Reham et al, ${ }^{62}$ studied correlations between oscillometry and spirometry on patients diagnosed with rheumathoid arthritis accociating ILD, and concluded that IOS can be used as an early screening technique to identify proximal and distal pulmonary tissue affection even before spirometry changes appear. Furthermore it facilitates the selection of patients needing further investigations to confirm the cause of increased lung resistance.

\section{Impairment of Lung Function Due to Exposure to Occupational Hazards or Smoking}

In an American study, Berger et $\mathrm{al}^{63,64}$ showed that the forced oscillometry technique has high capacity in early diagnostis of airway disease. In their study they performed oscillometry and spirometry on symptomatic subjects exposed to the World Trade Center dust, and while spirometry values were normal, they registered modifications on oscillometric parameters. An older study assessing the secondary effects of smoking habits of miners concluded that the effect of occupational exposure on the central airways can be registered by oscillometry, but not the effect of smoking. ${ }^{65}$ A study performed in Brazil by de 
Sá et $\mathrm{al}^{66}$ on asbestos exposed workers showed that oscillometry can be used as a screening tool in asbestos management and eradication. Other publications show that oscillometry is as useful as spirometry in analyzing lung function impairment due to smoking or occupational hazards. ${ }^{6,67}$

It is well known that, even with normal spirometry values smokers develop symptoms and small airway impairment in time. ${ }^{68-70} \mathrm{~A}$ study performed on smokers showed that development of symptoms was correlated with spirometry and oscillometry parameters. They did not determine whether there is clinical significance in the obtained altered values. ${ }^{71}$ Berger et al ${ }^{72}$ conducted a study on asymptomatic smoker subjects, which concluded that there was small airway impairment in oscillometric parameters, in subjects associating emphysema detected on computer tomograph and inflammation. These subjects could not yet be diagnosed with COPD according to Gold criteria.

\section{Assessing Small Airways Proprieties}

Small airways disease is one of the current hot topics in publications. The correlation between small airway dysfunction and oscillometry has also been studied. ${ }^{72,73}$ High values of R5-R20 may indicate small airway disfunction. ${ }^{74}$ A large cohort study (ATLANTIS), conducted in nine countries, on 773 asthmatic subjects, published by Postma et $a l,{ }^{75}$ revealed that SAD may be present in all GINA stages of asthma, the prevalence is higher in advanced stages (GINA 5). They also showed that oscillometry can be included in routine diagnose testing in clinical practice. Bhatawadekar et $\mathrm{al}^{76}$ quantified bronchodilator response in the large and the small airways of healthy and asthmatic subjects, revealing that bronchodilator response was more important in the small airways of asthmatic subjects. They found low-frequency reactance and derived elastance relevant for the measurement of distal airway function. A study published by Shi et al ${ }^{77}$ revealed that for the detection of poor control in the case of asthmatic children, between the spirometric parameters (FVC, FEV1, and FEF25-75) and the oscillometry parameters, the most suggestive parameters were found in IOS (impulse oscillometry). A Chinese study revealed values of R5-R20 are corelated with distal airways impairment in the case of heavy smokers and early stages of COPD, and also with particularities evidenced on endobronchial optical coherence tomography. ${ }^{78}$ Furthermore, another study suggests that both IOS and spirometry have matching value in diagnosing small airway disorders in bronchiectasis in mild and moderate stages. ${ }^{79}$ Foy et al ${ }^{80}$ very recently published a study that concluded that, although the small airways have increased resistance in moderate-to -severe asthma, their dilatation in deep breathing is not affected (without bronchial challenge), wich leads to the fact that targeted therapy of small airways is also needed for disease improvement.

\section{Central Airways Obstruction}

A study published by Hnad et al ${ }^{81}$ revealed evidence of the usefulness of oscillometry in the assessment of the central airway obstruction. The advantage of oscillometry, being non-invasive and also effort-independent, makes it a sustainable test for differentiating fixed and variable obstruction of central airways, also for monitoring before and after procedures, like bronchoscopy. Another study concluded that the therapeutic results can also be estimated in the case of patients with central airway obstruction using the oscillometric parameter Rrs $20{ }^{82}$

\section{Cystic Fibrosis}

Most studies regarding cystic fibrosis have been published on children. ${ }^{83-85}$ Research on oscillometryc parameters in cystic fibrosis showed an increase in Rrs5, Fres, and a decrease of Xrs5 in phases of the exacerbation of the disease, and an improvement of these parameters after treatment. ${ }^{86}$ A Brazilian study on 26 cystic fibrosis patients that consisted in assessment of lung volume by computer tomography and pulmonary function tests, revealed that hypoventilated regions of the lungs correlate with increasing restrictive parameters of oscillometry and also with reduced diffusing capacity of the lungs. ${ }^{87}$

\section{Monitoring Lung Mechanics During Mechanical Ventilation and Sleep}

The oscillometry's use in modified lung mechanics during ventilation and sleep studies has been widely researched. The impedance values of the respiratory system may have a contribution in invasive and also non-invasive ventilator settings. ${ }^{88-93}$ In sleep apnea impedance it can be followed during the breathing cycle, and changes can be detected when apneas or hypopneas appear. ${ }^{94}$ A Chinese study showed that the association between the oscillometric value of reactance and obstructive sleep apnea can be developed in the case of stenosis of the upper airways. ${ }^{88}$ Another study published by $\mathrm{McDowe}^{95}$ revealed data on 
usefulness of the IOS in monitoring obstructive sleep apnea after CPAP therapy. The study included 18 patients with obstructive sleep apnea that underwent CPAP therapy for 3 months. Their results showed that there was a significant decrease of resistance and reactance parameters after therapy, concluding that IOS can be used for monitoring therapy.

\section{Neuromuscular Diseases}

An older Belgian study performed on 16 patients with ankylosing spondylitis and seven with kyphoscoliosis, conducting pulmonary function tests, including oscillometry, revealed differences in the resistance and the reactance of the two diseases correlated with the severity of the restriction. $^{96,97}$

\section{Other Diseases - Graft Function, Lung Transplant, Sickle-Cell Disease}

In addition to the disease categories mentioned above, modification patterns in FOT parameters were studied also in the case of patients with lung transplant. A case-report study revealed oscillometry's use in the pulmonary function testing of patients in early stages after lung transplant, who cannot perform spirometry, due to post-operative pain and poor cooperation in forced expiratory maneuvers. Researchers concluded that the test was useful in evaluation of small airways in the case of critically ill patients, and may help in diagnosing acute graft rejection. ${ }^{98}$ Another study performed in Poland, on 25 transplanted patients, showed that IOS may be used in the assessment of chronic lung allograft dysfunction. ${ }^{99}$ A recent Chinese study, performed on 156 lung-transplanted patients, shows that Oscillometry identified physiological changes associated with grade 2 acute cell rejection that were not observed on spirometry and it's usefor graft monitoring after a lung transplant. ${ }^{100}$ Although it's not an adult-based study, a group of researchers from Pennsylvania found that oscillometry was more feasible than spirometry in children with Sickle-Cell disease, because it can be performed on children of young age, and it has greater sensibility to bronchodilatationresponse. $^{101}$

\section{Limitations}

Lately oscillometry became a trendy and promising tool in lung mechanics' assessment. However, there are substantial limitations of this method. Standardization documents still need improvement, especially on normative values. Also, the comparison between different devices presents difficulty and requires further study. In the absence of this data, the ERS Task Force recommends that reference values should be derived from a device that is most similar to the device in use. ${ }^{8}$ Although its utility in obstructive diseases seems clear, there is place for further research in oscillometric parameters in restrictive patterns. When comparing broncho-dilatator response, oscillometry and spirometry parameters may be discordant. Most of the studies published at the time are conducted on a small scale of patients, which makes it difficult to use it as a strong diagnostic tool. ${ }^{102}$

\section{Future Directions}

Further research is needed on quality control methods for parameters, covering wide age ranges and in various pulmonary diseases and clinical areas (the intensive care, population screening). Implementing oscillometry to geriatric and pediatric clinics could be important in diagnosis and monitoring diseases, facilitating the adjustments of therapy. Interstitial lung diseases with oscillometry need detailed research, since a radiation-free assessment in monitoring disease progression could be very beneficial. Oscillometry can be a sensitive tool for diagnosing early stages of fibrosis (even before spirometric changes). Furthermore, with new fields being studied, we can anticipate that the use of this technique will continue to expand in research. The development of new easier to use and portable devices and the acquired knowledge on interpreting oscillometry parameters, will hopefully make this technique more accepted and useful for daily practice.

\section{Conclusions}

Both methods' (FOT and IOS) measurement techniques are effective in assessment of airflow limitation. Since it is performed on tidal breathing, there is no need for active cooperation of the patients, it is suitable for both children and elderly patients, and for those who cannot perform spirometry. The technique is reproducible, although the variability is more pronounced than in spirometry. Recently, the recommendations for standardization in measurements were updated (ERS 2019), but there is a requirement for elaborating the standardization of reference values and thresholds, especially in the case of adults. It seems that the role of oscillometry is relevant in observation of changes over time in chronic diseases, also in investigating broncho-motor responses of airways, although significant changes in both tests 
need further study. Interest in impulse oscillometry is expanding worldwide, new applications in physiology and various clinical conditions are arising.

\section{Disclosure}

The authors report no conflicts of interest in this work.

\section{References}

1. Pride NB. Forced oscillation techniques for measuring mechanical properties of the respiratory system. Thorax. 1992;47(4):317-320. doi:10.1136/thx.47.4.317

2. Dubois A, Brody A, Lewis DBBJ. Mechanics of lungs and chest in man. J Appl Physiol - Am J Physiol. 1956;8:587-594. doi:10.1152/ jappl.1956.8.6.587

3. Bickel S, Popler J, Lesnick B, Eid N. Impulse oscillometry: interpretation and practical applications. Chest. 2014;146(3):841-847. doi:10.1378/chest.13-1875

4. Goldman MD, Saadeh C, Ross D. Clinical applications of forced oscillation to assess peripheral airway function. Respir Physiol Neurobiol. 2005;148(1-2SPEC. ISS):179-194. doi:10.1016/j. resp. 2005.05 .026

5. Goldman MD. Clinical application of forced oscillation. Pulm Pharmacol Ther. 2001;14(5):341-350. doi:10.1006/pupt.2001.0310

6. Oostveen E, MacLeod D, Lorino H, et al. The forced oscillation technique in clinical practice: methodology, recommendations and future developments. Eur Respir J. 2003;22(6):1026-1041. doi:10.1183/09031936.03.00089403

7. Johnston R PFT blog Observations, opinions and ideas about pulmonary function testing. Oscillometry. Available from: https:// www.pftforum.com/blog/? $=$ =scillometry\&submit=Search. Accessed November 3, 2020.

8. King GG, Bates J, Berger KI, et al. Technical standards for respiratory oscillometry. Eur Respir J. 2020;55:2. doi:10.1183/ 13993003.00753-2019

9. Watts JC, Farah CS, Seccombe LM, et al. Measurement duration impacts variability but not impedance measured by the forced oscillation technique in healthy, asthma and COPD subjects. ERJ Open Res. 2016;2(2):1-7. doi:10.1183/23120541.00094-2015

10. Jensen A, Atileh H, Suki B, Ingenito EP, Lutchen AKR. Selected Contribution: airway caliber in healthy and asthmatic subjects: effects of bronchial challenge and deep inspirations. $J$ Appl Physiol. 2003;94:1242-1252.

11. Salome CM, Thorpe CW, Diba C, et al. Airway re-narrowing following deep inspiration in asthmatic and nonasthmatic subjects. Eur Respir J. 2003;22(1):62-68. doi:10.1183/09031936.03.00117502

12. Slats AM, Janssen K, Van Schadewijk A, et al. Bronchial inflammation and airway responses to deep inspiration in asthma and chronic obstructive pulmonary disease. Am J Respir Crit Care Med. 2007;176(2):121-128. doi:10.1164/rccm.200612-1814OC

13. Daróczy B, Hantos Z. Generation of optimum pseudorandom signals for respiratory impedance measurements. Int $J$ Biomed Comput. 1990;25(1):21-31. doi:10.1016/0020-7101(90)90058-3

14. David W, Dellaca RL. Oscillation mechanics of the respiratory system: applications to lung diseaseno title. Crit Rev Biomed Eng. 2011;39(4):337-359. doi:10.1615/CritRevBiomedEng.v39.i4.60

15. Smith HJ, Reinhold P, Goldman MD. Forced oscillation technique and impulse oscillometry. Lung Funct Test. 2005;2005:72-105. doi:10.1183/1025448x.00031005

16. de Oliveira Jorge PP, de Lima JHP, Chong e Silva DC, et al. Impulse oscillometry in the assessment of children's lung function. Allergol Immunopathol (Madr). 2019;47(3):295-302. doi:10.1016/ j.aller.2018.03.003
17. David W, Kaczkaa B. Oscillation mechanics of the respiratory system: applications to lung disease. Crit Rev Biomed Eng. 2001;29(3):375-385.

18. Brashier B, Salvi S. Measuring lung function using sound waves: role of the forced oscillation technique and impulse oscillometry system. Breathe. 2015;11(1):57-65. doi:10.1183/20734735.020514

19. Dionísio GH, Dos Santos DO, Perossi L, de Paula MH, de Souza HCD, Gastaldi AC. The influence of different mouthpieces on impulse oscillometry results. Respir Care. 2018;63(5):565-572. doi: $10.4187 /$ respcare. 05471

20. Desiraju K, Agrawal A. Impulse oscillometry: the state-of-art for lung function testing. Lung India. 2016;33(4):410-416. doi:10.4103/0970-2113.184875

21. Oostveen E, Boda K, Van Der Grinten CPM, et al. Respiratory impedance in healthy subjects: baseline values and bronchodilator response. Eur Respir J. 2013;42(6):1513-1523. doi:10.1183/ 09031936.00126212

22. Tanimura K, Hirai T, Sato S, et al. Comparison of two devices for respiratory impedance measurement using a forced oscillation technique: basic study using phantom models. $J$ Physiol Sci. 2014;64 (5):377-382. doi:10.1007/s12576-014-0329-4

23. Zimmermann SC, Watts JC, Bertolin A, Jetmalani K, King GG, Thamrin C. Discrepancy between in vivo and in vitro comparisons of forced oscillation devices. J Clin Monit Comput. 2018;32 (3):509-512. doi:10.1007/s10877-017-0050-y

24. Kalchiem-Dekel O, Hines SE. Forty years of reference values for respiratory system impedance in adults: 1977-2017. Respir Med. 2018;136(January):37-47. doi:10.1016/j.rmed.2018.01.015

25. Schulz H, Flexeder C, Behr J, et al. Reference values of impulse oscillometric lung function indices in adults of advanced age. PLoS One. 2013;8:5. doi:10.1371/journal.pone.0063366

26. Dandurand RJ, Lavoie J-P, Lands LC, Hantos Z. Comparison of oscillometry devices using active mechanical test loads. ERJ Open Res. 2019;5(4):00160-02019. doi:10.1183/23120541.00160-2019

27. Palacios MÁD, Marín DH, Valero AG, Hernández NC, Barona CT, de Rojas DHF. Correlation between impulse oscillometry parameters and asthma control in an adult population. J Asthma Allergy. 2019;12:195-203. doi:10.2147/JAA.S193744

28. Diong B, Singh K, Menendez R. Effects of two inhaled corticosteroid/long-acting beta-agonist combinations on small-airway dysfunction in mild asthmatics measured by impulse oscillometry. J Asthma Allergy. 2013;(6):109-116. doi:10.2147/ JAA.S48827

29. Da Costa GM, Faria ACD, Di Mango AMGT, Lopes AJ, Lopes De Melo P. Respiratory impedance and response to salbutamol in healthy individuals and patients with COPD. Respiration. 2014;88 (2):101-111. doi:10.1159/000362691

30. Diba C, King GG, Berend N, Salome CM. Improved respiratory system conductance following bronchodilator predicts reduced exertional dyspnoea. Respir Med. 2011;105(9):1345-1351. doi:10.1016/j.rmed.2011.03.013

31. Milne S, Hammans C, Watson S, Farah CS, Thamrin C, King GG Bronchodilator responses in respiratory impedance, hyperinflation and gas trapping in COPD. COPD J Chronic Obstr Pulm Dis. 2018;15(4):341-349. doi:10.1080/15412555.2018.1458217

32. Hozawa S, Terada M, Hozawa M. Comparison of the effects of budesonide/formoterol maintenance and reliever therapy with fluticasone/salmeterol fixed-dose treatment on airway inflammation and small airway impairment in patients who need to step-up from inhaled corticosteroid monotherapy. Pulm Pharmacol Ther. 2014;27(2):190-196. doi:10.1016/j.pupt.2013. 12.003

33. Nakaji H, Petrova G, Matsumoto H, et al. Effects of 24-week add-on treatment with ciclesonide and montelukast on small airways inflammation in asthma. Ann Allergy Asthma Immunol. 2013;110(3):198-203.e3. doi:10.1016/j.anai.2012.12.016 
34. Timmins SC, Diba C, Schoeffel RE, Salome CM, King GG, Thamrin C. Changes in oscillatory impedance and nitrogen washout with combination fluticasone/salmeterol therapy in COPD. Respir Med. 2014;108(2):344-350. doi:10.1016/j.rmed.2013.10.004

35. Akamatsu T, Shirai T, Shimoda Y, et al. Forced oscillation technique as a predictor of FEV1 improvement in asthma. Respir Physiol Neurobiol. 2017;236:78-83. doi:10.1016/j.resp.2016.11.013

36. Segal LN, Goldring RM, Oppenheimer BW, et al. Disparity between proximal and distal airway reactivity during methacholine challenge. COPD J Chronic Obstr Pulm Dis. 2011;8(3):145-152. doi:10.3109/15412555.2011.560127

37. Mahadev S, Farah CS, King GG, Salome CM. Obesity, expiratory flow limitation and asthma symptoms. Pulm Pharmacol Ther. 2013;26(4):438-443. doi:10.1016/j.pupt.2012.05.004

38. de Albuquerque CG, de Andrade FMD, de Rocha MAA, et al. Determining respiratory system resistance and reactance by impulse oscillometry in obese individuals. $J$ Bras Pneumol. 2015;41(5):422-426. doi:10.1590/S1806-37132015000004517

39. Vink GR, Arets HGM, Van der Laag J. Van der Ent CK. Impulse oscillometry: a measure for airway obstruction. Pediatr Pulmonol. 2003;35(3):214-219. doi:10.1002/ppul.10235

40. Schulze J, Smith HJ, Fuchs J, et al. Methacholine challenge in young children as evaluated by spirometry and impulse oscillometry. Respir Med. 2012;106(5):627-634. doi:10.1016/j.rmed.2012.01.007

41. Choi SH, Sheen YH, Kim MA, et al. Clinical implications of oscillatory lung function during methacholine bronchoprovocation testing of preschool children. Biomed Res Int. 2017;2017:1-9. doi: $10.1155 / 2017 / 9460190$

42. Naji N, Keung E, Kane J, Watson RM, Killian KJ, Gauvreau GM. Comparison of changes in lung function measured by plethymography and IOS after bronchoprovocation. Respir Med. 2013;107 (4):503-510. doi:10.1016/j.rmed.2012.12.022

43. Meraz EG, Nazeran $H$, Ramos CD, Nava P, Diong B, Goldman MD. Analysis of impulse oscillometric measures of lung function and respiratory system model parameters in small airway-impaired and healthy children over a 2-year period. Biomed Eng Online. 2011;10:1-21. doi:10.1186/1475-925X-10-21

44. Galant SP, Komarow HD, Shin HW, Siddiqui S, Lipworth BJ. The case for impulse oscillometry in the management of asthma in children and adults. Ann Allergy Asthma Immunol. 2017;118 (6):664-671. doi:10.1016/j.anai.2017.04.009

45. Carr TF, Altisheh R, Zitt M. Small airways disease and severe asthma. World Allergy Organ J. 2017;10(1):1-9. doi:10.1186/ s40413-017-0153-4

46. Gallucci M, Carbonara P, Pacilli AMG, Di Palmo E, Ricci G, Nava S. Use of symptoms scores, spirometry, and other pulmonary function testing for asthma monitoring. Front Pediatr. 2019;7 (MAR):1-12. doi:10.3389/fped.2019.00054

47. Larsen GL, Morgan W, Heldt GP, et al. Impulse oscillometry versus spirometry in a long-term study of controller therapy for pediatric asthma. J Allergy Clin Immunol. 2009;123(4):861-867.e1. doi:10.1016/j.jaci.2008.10.036

48. Lipworth BJ, Jabbal S. What can we learn about COPD from impulse oscillometry? Respir Med. 2018;139(February):106-109. doi:10.1016/j.rmed.2018.05.004

49. Zerah F, Lorino AM, Lorino H, Harf A, Macquin-Mavier I. Forced oscillation technique vs spirometry to assess bronchodilatation in patients with asthma and COPD. Chest. 1995;108(1):41-47. doi:10.1378/chest.108.1.41

50. Nikkhah M, Amra B, Eshaghian A, et al. Comparison of impulse osillometry system and spirometry for diagnosis of obstructive lung disordersle. Tanaffos $J$. 2011;10:19-25.

51. Kolsum U, Borrill Z, Roy K, et al. Impulse oscillometry in COPD: identification of measurements related to airway obstruction, airway conductance and lung volumes. Respir Med. 2009;103 (1):136-143. doi:10.1016/j.rmed.2008.07.014
52. Wei X, Shi Z, Cui Y, et al. Impulse oscillometry system as an alternative diagnostic method for chronic obstructive pulmonary disease. Med (United States). 2017;96:46. doi:10.1097/MD.0000000000008543

53. Crim C, Celli B, Edwards LD, et al. Respiratory system impedance with impulse oscillometry in healthy and COPD subjects: ECLIPSE baseline results. Respir Med. 2011;105(7):1069-1078. doi:10.1016/ j.rmed.2011.01.010

54. Piorunek T, Kostrzewska M, Cofta S, et al. Impulse oscillometry in the diagnosis of airway resistance in chronic obstructive pulmonary disease. Advs Exp Med Biol Neurosci Respir. 2015;7:47-52.

55. Eddy RL, Westcott A, Maksym GN, Parraga G, Dandurand RJ. Oscillometry and pulmonary magnetic resonance imaging in asthma and COPD. Physiol Rep. 2019;7(1):1-12. doi:10.14814/phy2.13955

56. Takeichi N, Yamazaki H, Fujimoto K. Comparison of impedance measured by the forced oscillation technique and pulmonary functions, including static lung compliance, in obstructive and interstitial lung disease. Int J COPD. 2019;14:1109-1118. doi:10.2147/ COPD.S198030

57. van Noord JA, Clément J, Cauberghs M, Mertens I, Van de Woestijne KP. Total respiratory resistance and reactance in patients with diffuse interstitial lung disease. Eur Respir J. 2(9):846-852.

58. Sugiyama A, Hattori N, Haruta Y, et al. Characteristics of inspiratory and expiratory reactance in interstitial lung disease. Respir Med. 2013;107(6):875-882. doi:10.1016/j.rmed.2013.03.005

59. Shirai T, Kurosawa H. Clinical application of the forced oscillation technique. Intern Med. 2016;55(6):559-566. doi:10.2169/ internalmedicine. 55.5876

60. Mori K, Shirai T, Mikamo M, et al. Respiratory mechanics measured by forced oscillation technique in combined pulmonary fibrosis and emphysema. Respir Physiol Neurobiol. 2013;185 (2):235-240. doi:10.1016/j.resp.2012.10.009

61. Mikamo M, Fujisawa T, Oyama Y, et al. Clinical significance of forced oscillation technique for evaluation of small airway disease in interstitial lung diseases. Lung. 2016;194(6):975-983. doi:10.1007/s00408-016-9949-1

62. Elkolalya RM, Gannaa SA, Elnaggarc MH. Impulse oscillometry, an aid or a substitute? Egypt J Bronchol. 2019;13:416-423. doi:10.4103/ejb.ejb_98_18

63. Ram J, Pineda-Cely J, Calhoun WJ. Forced oscillometry: a new tool for assessing airway function - is it ready for prime time? J Allergy Clin Immunol Pract. 2019;7(8):2861-2862. doi:10.1016/j.jaip.2019.07.037

64. Berger KI, Goldring RM, Oppenheimer BW. Should oscillometry be used to screen for airway disease?. Chest. 2015;148 (5):1131-1135. doi:10.1378/chest.15-0106

65. Peslin R, Pham QT, Teculescu D, Gallina C. Comparative value of respiratory input and transfer impedances in field studies. Eur Physiopathol Respir. 1987;23(1):37-42.

66. Sá PM, Castro HA, Lopes AJ, De Melo PL. Early diagnosis of respiratory abnormalities in asbestos-exposed workers by the forced oscillation technique. PLoS One. 2016;11(9):1-28. doi:10.1371/journal.pone.0161981

67. Pham QT, Bourgkard E, Chau N, et al. Forced oscillation technique (FOT): a new tool for epidemiology of occupational lung diseases? Eur Respir J. 1995;8(8):1307-1313. doi:10.1183/09031936.95.08081307

68. Lambert AA, Bhatt SP. Respiratory symptoms in smokers with normal spirometry: clinical significance and management considerations. Curr Opin Pulm Med. 2019;25(2):138-143. doi:10.1097/MCP.0000000000000550

69. Faria ACD, Lopes AJ, Jansen JM, Melo PL. Evaluating the forced oscillation technique in the detection of early smoking-induced respiratory changes. Biomed Eng Online. 2009;8:22. doi:10.1186/ 1475-925X-8-22

70. Shinke H, Yamamoto M, Hazeki N, Kotani Y, Kobayashi K, Nishimura Y. Visualized changes in respiratory resistance and reactance along a time axis in smokers: a cross-sectional study. Respir Investig. 2013;51(3):166-174. doi:10.1016/j.resinv.2013.02.006 
71. Jetmalani K, Thamrin C, Farah CS, et al. Peripheral airway dysfunction and relationship with symptoms in smokers with preserved spirometry. Respirology. 2018;23(5):512-518. doi:10.1111/resp.13 215

72. Berger KI, Pradhan DR, Goldring RM, Oppenheimer BW, Rom WN, Segal LN. Distal airway dysfunction identifies pulmonary inflammation in asymptomatic smokers. ERJ Open Res. 2016;2 (4):1-10. doi:10.1183/23120541.00066-2016

73. Pisi R, Tzani $P$, Aiello $M$, et al. Small airway dysfunction by impulse oscillometry in asthmatic patients with normal forced expiratory volume in the 1st second values. Allergy Asthma Proc. 2013;34(1):14-20. doi:10.2500/aap.2013.34.3641

74. Usmani OS, Singh D, Spinola M, Bizzi A, Barnes PJ. The prevalence of small airways disease in adult asthma: A systematic literature review. Respir Med. 2016;116:19-27. doi:10.1016/j. rmed.2016.05.006

75. Postma DS, Brightling C, Baldi S, et al. Exploring the relevance and extent of small airways dysfunction in asthma (ATLANTIS): baseline data from a prospective cohort study. Lancet Respir Med. 2019;7(5):402-416. doi:10.1016/S2213-2600(19)30049-9

76. Bhatawadekar SA, Leary D, de Lange V, et al. GNM 1. Reactance and elastance as measures of small airways response to bronchodilator in asthma. $J$ Appl Physiol. 2019;127(6):1772-1781. doi:10. 1152/japplphysiol.01131.2018

77. Shi Y, Aledia AS, Tatavoosian AV, Vijayalakshmi S, Galant SP, George SC. Relating small airways to asthma control by using impulse oscillometry in children. $J$ Allergy Clin Immunol. 2012;129(3):671-678. doi:10.1016/j.jaci.2011.11.002

78. Su ZQ, Guan WJ, Li SY, et al. Significances of spirometry and impulse oscillometry for detecting small airway disorders assessed with endobronchial optical coherence tomography in COPD. Int J COPD. 2018;13:3031-3044. doi:10.2147/COPD.S172639

79. Guan WJ, Yuan JJ, Gao YH, et al. Impulse oscillometry and spirometry small-airway parameters in mild to moderate bronchiectasis. Respir Care. 2016;61(11):1513-1522. doi:10.4187/ respcare. 04710

80. Foy BH, Natarajan S, Munawar A, Soares M, Thorpe J, OwersBradley J. Characterising the role of small airways in severe asthma using low frequency forced oscillations: a combined computational and clinical approach. Respir Med. 2020;170:106022. doi:10.1016/ j.rmed.2020.106022

81. Handa H, Huang J, Murgu SD, et al. Assessment of central airway obstruction using impulse oscillometry before and after interventional bronchoscopy. Respir Care. 2014;59(2):231-240. doi:10. 4187/respcare.02094

82. Yasuo M, Kitaguchi Y, Kinota F, et al. Usefulness of the forced oscillation technique in assessing the therapeutic result of tracheobronchial central airway obstruction. Respir Investig. 2018;56 (3):222-229. doi:10.1016/j.resinv.2018.01.005

83. Ren CL, Rosenfeld M, Mayer OH, et al. Analysis of the associations between lung function and clinical features in preschool children with Cystic Fibrosis. Pediatr Pulmonol. 2012;47 (6):574-581. doi:10.1002/ppul.21590

84. Nielsen KG, Pressler T, Klug B, Koch C, Bisgaard H. Serial lung function and responsiveness in cystic fibrosis during early childhood. Am J Respir Crit Care Med. 2004;169(11):1209-1216. doi:10.1164/rccm.200303-347oc

85. Kerby GS, Rosenfeld M, Ren CL, et al. Lung function distinguishes preschool children with CF from healthy controls in a multi-center setting. Pediatr Pulmonol. 2012;47(6):597-605. doi:10.1002/ ppul.21589

86. Sakarya A, Uyan ZS, Baydemir C, et al. Evaluation of children with cystic fibrosis by impulse oscillometry when stable and at exacerbation. Pediatr Pulmonol. 2016;51(11):1151-1158. doi:10. $1002 /$ ppul.23449
87. Lacerda LS, Lopes AJ, Carvalho ARS, et al. The role of multidetector computed tomography and the forced oscillation technique in assessing lung damage in adults with cystic fibrosis. Respir Care. 2018;63(4):430-440. doi:10.4187/respcare.05 815

88. Badia JR, Farré R, Kimoff RJ, et al. Clinical application of the forced oscillation technique for CPAP titration in the sleep apnea/ hypopnea syndrome. Am J Respir Crit Care Med. 1999;160 (5I):1550-1554. doi:10.1164/ajrccm.160.5.9902085

89. Liu H, Ni W, Zhao J, Xiong S, Xu Y, Zhang Z. The diagnosis value and its implication of impulse oscillometry in obstructive sleep apnea syndrome patients. $J$ Tongji Med Univ. 2001;20 (4):280-282. doi:10.1007/bf02888179

90. Peslin R, et al. Respiratory mechanics studied by forced oscillations during artificial ventilation. Eur Respir J. 6:772-846.

91. Lanteri CJ, Kano S, Duncan AW, Sly PD. Changes in respiratory mechanics in children undergoing cardiopulmonary bypass. $\mathrm{Am}$ J Respir Crit Care Med. 1995;152(6I):1893-1900. doi:10.1164/ ajrccm.152.6.8520752

92. Farré R, Mancini M, Rotger M, Ferrer M, Roca J, Navajas D. Oscillatory resistance measured during noninvasive proportional assist ventilation. Am J Respir Crit Care Med. 2001;164 (5):790-794. doi:10.1164/ajrccm.164.5.2102049

93. NAVAJAS D, FARRÉ R, ROTGER M, et al. Assessment of airflow obstruction during CPAP by means of forced oscillation in patients with sleep apnea. Am J Respir Crit Care Med. 1998;157(5PART I): 1526-1530. doi:10.1164/ajrccm.157.5.9710026

94. Beydon L, Malassine P, Lorino AM, et al. Respiratory resistance by end-inspiratory occlusion and forced oscillations in intubated patients. J Appl Physiol. 1996;80(4):1105-1111. doi:10.1152/ jappl.1996.80.4.1105

95. Abdeyrim A, Li NF, Shao L, et al. What can impulse oscillometry and pulmonary function testing tell us about obstructive sleep apnea: a case-control observational study? Sleep Breath. 2016;20 (1):61-68. doi:10.1007/s11325-015-1185-z

96. McDowell GC. Impulse oscillometry in obstructive sleep apnoea syndrome and its response to CPAP: feasibility and insights into pulmonary mechanics Thorax. Thorax. 2019; $74: 162-163$.

97. Van Noord JA, Cauberghs M, Van De Woestijne KP, Demedts M. Total respiratory resistance and reactance in ankylosing spondylitis and kyphoscoliosis. Eur Respir J. 1991;4(8):945-951.

98. Hamakawa H, Sakai H, Ayuko TJZ, et al. Forced oscillation technique as a non-invasive assessment for lung transplant recipientsno title. Biol Med. 2010;662:293-298.

99. Ochman M, Wojarski J, Wiórek A, et al. Usefulness of the impulse oscillometry system in graft function monitoring in lung transplant recipients. Transplant Proc. 2018;50(7):2070-2074. doi:10.1016/j. transproceed.2017.12.060

100. Cho E, Wu JKY, Birriel DC, et al. Airway oscillometry detects spirometric-silent episodes of acute cellular rejection. Am J Respir Crit Care Med. 2020;201(12):1536-1544. doi:10.1164/rccm. 201908-1539OC

101. Mondal P, Yirinec A, Midya V, et al. Diagnostic value of spirometry vs impulse oscillometry: a comparative study in children with sickle cell disease. Pediatr Pulmonol. 2019;54(9):1422-1430. doi:10.1002/ppul.24382

102. Bednarek M, Grabicki M, Piorunek T, Batura-Gabryel H. Current place of impulse oscillometry in the assessment of pulmonary diseases. Respir Med. 2020;170:105952. doi:10.1016/j.rmed.2020. 105952

103. Brown NJ, Xuan W, Salome CM, et al. Reference equations for respiratory system resistance and reactance in adults. Respir Physiol Neurobiol. 2010;172(3):162-168. doi:10.1016/j.resp.2010. 05.013 
104. Fujiwara K. [Preoperative lung function tests using impulse oscillometry]. Masui. 2010 Feb;59(2):169-178. Japanese. PMID: 20169952.

105. Li F, Wang X. Analysis of the normal Values of pulmonary function by impulse oscillometry in healthy adults in Lanzhou. Prog Microbiol Immunol. 2012;40:34-37.
106. Ribeiro FCV, Lopes AJ, Melo PL. Reference values for respiratory impedance measured by the forced oscillation technique in adult men and women. Clin Respir J. 2018;12(6):2126-2135. doi:10. $1111 /$ crj. 12783

\section{Publish your work in this journal}

Therapeutics and Clinical Risk Management is an international, peerreviewed journal of clinical therapeutics and risk management, focusing on concise rapid reporting of clinical studies in all therapeutic areas, outcomes, safety, and programs for the effective, safe, and sustained use of medicines. This journal is indexed on PubMed Central, CAS,
EMBase, Scopus and the Elsevier Bibliographic databases. The manuscript management system is completely online and includes a very quick and fair peer-review system, which is all easy to use. Visit http://www.dovepress.com/testimonials.php to read real quotes from published authors. 